\title{
Assessment of Chlamydia trachomatis, Neisseria gonorrhoeae, and Mycobacterium tuberculosis infections in women undergoing laparoscopy: the role of peritoneal fluid sampling
}

\author{
Miroslav Dragic, ${ }^{1}$ Patrizia Posteraro, ${ }^{2}$ Carla Marani, ${ }^{3}$ Maria Emanuela Natale, ${ }^{3}$ \\ Alessia Vecchioni, ${ }^{1}$ Maurizio Sanguinetti, ${ }^{4}$ Chiara de Waure, ${ }^{1}$ Brunella Posteraro ${ }^{1}$ \\ ${ }^{1}$ Institute of Public Health, Section of Hygiene, Sacro Cuore Catholic University, Rome; ${ }^{2}$ Clinical \\ Laboratory, San Carlo Hospital, Rome; ${ }^{3}$ Division of Pathology, San Carlo Hospital, Rome; \\ ${ }^{4}$ Institute of Microbiology, Sacro Cuore Catholic University, Rome, Italy
}

\section{Summary}

Background. Aim of this study was to assess the role of peritoneal fluid sampling for detection of bacterial infections due to Chlamydia trachomatis (CT), Neisseria gonorrhoeae (NG), and Mycobacterium tuberculosis (MT) in women undergoing laparoscopic investigation. The potential link between microbiological positive result(s) and types of gynecological pathology was also evaluated.

Materials and Methods. A large sample of women $(\mathrm{n}=1377)$ with their peritoneal fluids taken laparoscopically was studied. Data of microbiological and clinical/histopathological findings were entered into a database from a retrospective chart review. Culture and/or microscopy were used to detect NG or MT infection, whereas CT infection was detected using a PCR-based test.

Results and Conclusions. Of all the patients (14 to 50 years aged),

\footnotetext{
Correspondence: Maurizio Sanguinetti, Institute of Microbiology, Università Cattolica del Sacro Cuore, Largo F. Vito 1, 00168 Rome, Italy.

Tel: +39.06.3054411 - Fax: +39.06 .3051152 .

E-mail: maurizio.sanguinetti@unicatt.it
}

Key words: Bacterial infection; PCR amplification; culture; laparoscopy; peritoneal fluid.

Contributions: MD, PP, CDW, BP, study concept and design; PP, CM, MEN, laboratory work and collection of data; MD, CDW, AV, MS, data analysis; PP, $\mathrm{BP}$ drafting of manuscript; $\mathrm{BP}$, MS, critical revision; all authors, final approval of the version to be published.

Conflict of interest: the authors declare no potential conflict of interest.

Received for publication: 29 May 2016.

Accepted for publication: 13 July 2016.

(C) Copyright M. Dragic et al., 2016

Licensee PAGEPress, Italy

Microbiologia Medica 2016; 31:6038

doi:10.4081/mm.2016.6038

This article is distributed under the terms of the Creative Commons Attribution Noncommercial License (by-nc 4.0) which permits any noncommercial use, distribution, and reproduction in any medium, provided the original author(s) and source are credited.
$463(33.6 \%)$ had endometriosis, 1179 (85.6\%) had a pathology/condition other than endometriosis, and 71 (5.2\%) had no pathology as histologically documented. None of the patients had peritoneal fluid samples positive for NG or MT. In contrast, 30 (2.2\%) of 1377 patients had peritoneal fluid samples positive for CT. Except for 3 women with no histopathological alteration, all the CT positive patients had either endometriosis $(n=12)$ or non-endometriosis $(n=13)$ pathology. Two remaining patients were diagnosed with both the pathologies. Accordingly, no significant association (OR) was found between CT positivity and pathology [only endometriosis, 1.13 (95\%CI, 0.30-4.20)]; [only non-endometriosis, $0.53(95 \% \mathrm{CI}, 0.15-1.87)]$. While confirming the low positivity rate for the CT molecular detection, the present data indicate the need for prospective studies to firmly establish the clinical usefulness of peritoneal fluid diagnostic in gynecological settings.

\section{Introduction}

Chlamydia trachomatis (CT) and Neisseria gonorrhoeae (NG) infections rank among the four most common bacterial sexually transmitted infections (STIs) worldwide (21), thus representing a great public health concern due to severity of their potential long-term sequelae in women. Indeed, both organisms are major causes of pelvic inflammatory disease (PID), which in untreated women can result in tubal factor infertility up to $40 \%$ of the cases (27). However, non-sexually transmitted infections caused by Mycobacterium tuberculosis (MT) can also cause infertility (22), and these infections are typically associated with high overall virulence (1). In particular, genital tuberculosis should always be considered in young patients who present with unexplained infertility (22).

Recently updated guidelines from the National Institute for Health and Clinical Excellence (NICE) recommend to routinely perform laparoscopic investigation in women with suspected tubal and other pelvic pathologies (i.e. endometriosis, previous ectopic pregnancy, etc.) (20). Thus, despite being an invasive, expensive, and labor-intensive procedure, laparoscopy (with direct tissue biopsy) remains the diagnostic gold standard, especially for genital tuberculosis (22). In addition, routine infertility/subfertility diagnostics include the CT antibody test to decide for laparoscopy or not in order to diagnose tubal pathology; nonetheless, the positive and negative predictive value of this test is such that many unnecessary laparoscopies are performed and many tubal pathology cases are undetected (13).

Taking advantage of a quasi-anecdotal evidence $(16,17)$, in many hospitals peritoneal fluid samples, taken at the time of laparoscopy, are 
usually submitted to microbiological examination in order to assess not only the presence of CT but also of NG and MT (3). In this context, but only for CT organism, it is noticeable that 18 (47.8\%) of 38 infertility patients did show peritoneal fluid CT infection and/or endometrial CT infection, whereas 8 of the 18 patients (5 of whom with PID) were negative for CT DNA in cervical samples (26).

In the present study, we aimed at assessing the role of peritoneal fluid diagnostic in CT, NG, and MT infections among fertility and nonfertility patients who were laparoscopically investigated at a referral hospital in Rome. Using microbiological PCR-based and/or culture tests, we calculated the prevalence of CT, NG, and MT infections in groups of women with different gynecological pathologies. Finally, results from these tests were evaluated by comparison with those of clinical and/or histopathological examinations.

\section{Materials and Methods}

\section{Patient samples and medical records collection}

We performed a retrospective data analysis of clinical samples for which microbiological examination was requested, that were obtained from child-bearing aged women hospitalized at the surgical ward of the Gynecology Unit (San Carlo Hospital of Rome) who had laparoscopy as a part of their fertility or non-fertility workup. The samples were all peritoneal fluids that were aspirated, and the washing of the pelvic peritoneum was made with $300 \mathrm{~mL}$ of saline solution followed by aspiration using a laparoscopic cannula during the surgery (22). The clinical samples were collected over a period of seven calendar years (20092015). The exclusion criteria were i) insufficient chart documentation for the diagnosis of reproductive disease, ii) malignant or borderline neoplasms, iii) HPV-related cervical lesions, and iv) blood-contaminated samples. The study was done according to good clinical practice.

Based on clinical and/or histopathological findings, patients were cate- gorized as having or not one or more of the following benign diseases/conditions: i) endometriosis of the ovary, ii) ovary pathologies other than endometriosis (i.e. cyst, dermoid cyst, polyp, etc.), iii) fallopian tube pathologies (i.e. hydatid cyst, ectopic pregnancy, etc.), and iv) uterus pathologies (i.e. leiomyoma, endometrial polyp, adenomyosis, etc.).

\section{Diagnostic tests}

The GEN-PROBE® APTIMA® Assay (APTIMA CT assay) for CT, a target amplification nucleic acid probe test, was used for detecting CT ribosomal RNA in all the peritoneal fluid samples sent to the Clinical Laboratory Unit of the above-mentioned San Carlo Hospital. All samples were also subjected to standard microbiological methods (microscopic examination, culture on primary media, and subsequent organism identification) for NG and MT detection.

\section{Statistical analysis}

Data analysis was performed using the SPSS software version 22.0. The results were reported by means of descriptive statistics (mean \pm SD; absolute or relative frequency), and data were analyzed using the Student $t$ test for continuous variables and the Chi square test or Fischer's exact test for categorical variables, depending on the sample size of subgroups. A $P$ value $<0.05$ was considered significant. Odds ratios with $95 \%$ confidence interval $(95 \% \mathrm{CI})$ were used to estimate the strength of association between CT, NG, or MT positive samples and different patient groups.

\section{Results}

In the study period, peritoneal fluid samples were obtained from women during routine laparoscopic investigation and were microbiologically tested for the detection of CT-specific nucleic acid and for the culture of NG and MT organisms. Figure 1 shows the flowchart of

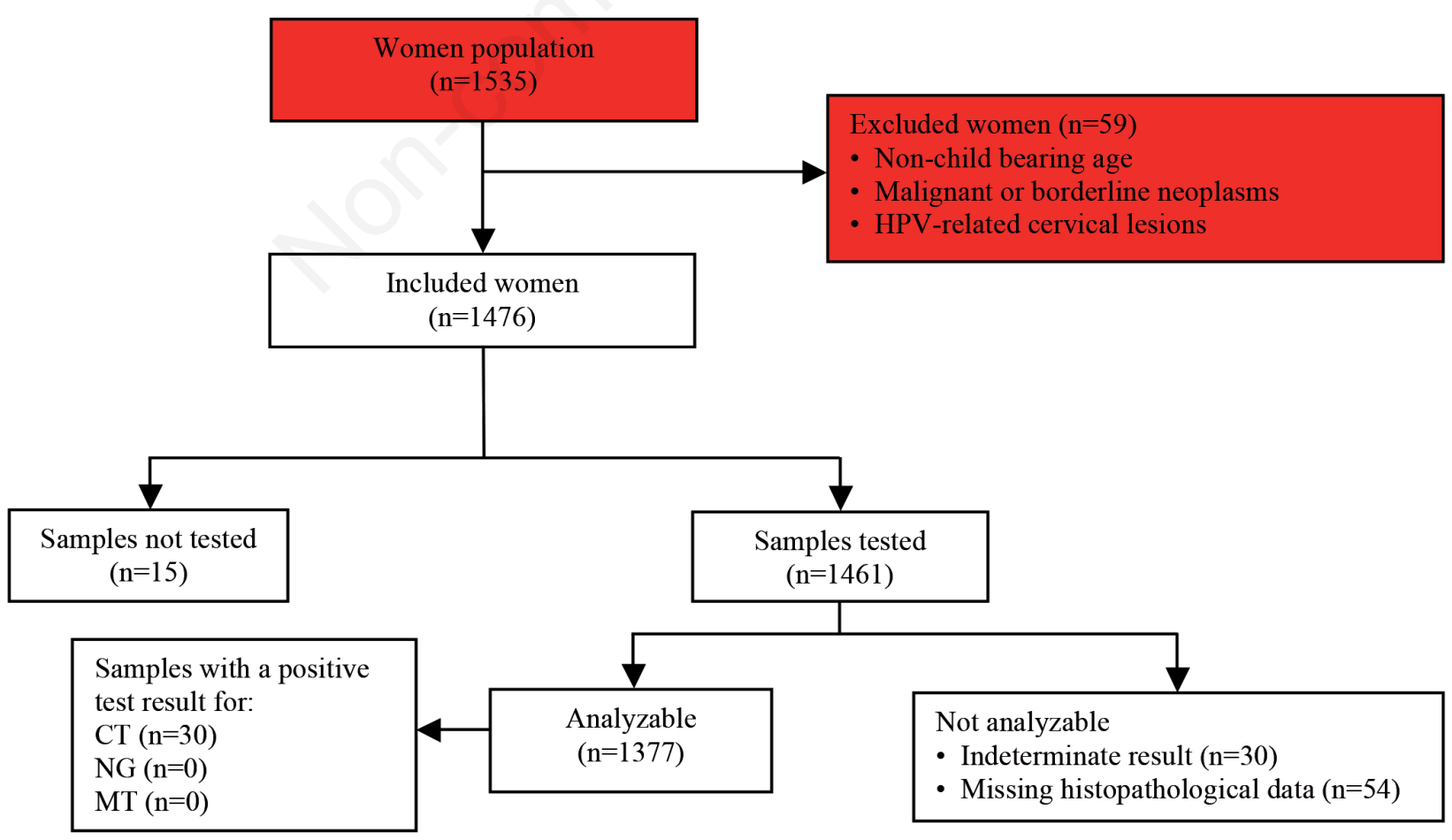

Figure 1. Flowchart of patients who underwent laparoscopy and their peritoneal fluids which were included in the analysis. 
selected women with their samples, which resulted in a total of 1377 samples included in the analysis. Patients' demographic and clinical characteristics are presented in Table 1. All the 1377 patients were women of child-bearing age (14-50 years); 463 (33.6\%) had endometriosis, whereas 1179 (85.6\%) had a pathology/condition other than endometriosis. No histopathological alterations were found in 71 (5.2\%) of 1377 patients.

Among the endometriosis patient group, the majority of cases occurred in women 31 to 40 years aged $(n=238,51.4 \%)$, whereas only 2 cases occurred in women $\leq 20$ years aged (Figure 2 ). Among the nonendometriosis patient group, most frequent pathologies were cysts $(n=179)$ and dermoid cysts $(n=139)$ of the ovary, leiomyomas $(n=482)$ and endometrial polyps $(n=109)$ of the uterus, and hydatid cysts of the fallopian tubes $(n=92)$. There were also 11 cases of ectopic pregnancy (Table 1).

As shown in Figure 1, none of the peritoneal fluid samples included in the study had a positive culture result for NG or MT; conversely, 30 (2.2\%) peritoneal fluid samples tested positive for CT molecular detection. Excluding 3 samples from women with no histopathological alteration, the remaining positive samples were from patients with endometriosis ( $n=12,40.0 \%$; of whom 2 diagnosed concomitantly with another ovarian or uterine pathology) and non-endometriosis pathologies such as ovarian ( $\mathrm{n}=5,16.6 \%)$, uterine ( $\mathrm{n}=7,23.3 \%)$, and tubal $(\mathrm{n}=1,3.3 \%)$. One patient had both hydatid and dermoid cysts and one patient had a leiomyoma diagnosed together with an ovarian cyst.

Considering women with no histopathological alteration as a reference [odds ratio $(\mathrm{OR})=1$ ], the analysis shown in Table 2 indicates that no significant association was found between a peritoneal fluid sample positive for CT and a histological diagnosis of only endometriosis [OR, 1.13 (95\%CI, 0.30-4.20)] or non-endometriosis [OR, 0.53 (95\%CI, 0.151.87)] pathology.

We also conducted a literature PubMed search for relevant articles on the topic of endometriosis and CT infection. The retrieved articles are summarized in Table 3 and are discussed below.

\section{Discussion and Conclusions}

Despite the increasingly recognized importance of extra-genital locations of NG and MT infections, that can now rely upon highly sensitive and specific detection tests such as nucleic acid amplification tests (NAATs), none of 1377 patients in our study had a peritoneal fluid that tested positive for NG or MT. However, we did not use a PCR-based method but rather conventional methods for detecting both the infec-

Table 1. Description of 1377 gynecological patients undergoing laparoscopy, who were included in the study.

\begin{tabular}{lcc} 
Characteristic/diagnosis & No.* & $\%$ \\
Age (years), mean \pm SD & $36.0 \pm 0.19$ & - \\
Pathology based on histological findings: & & \\
Endometriosis & 463 & 33.6 \\
Ovarian other than endometriosis & 424 & 30.8 \\
Fallopian tube & 119 & 8.6 \\
Fallopian tube, ectopic pregnancy & 11 & 0.8 \\
Uterine & 636 & 46.2 \\
Uterine, leiomyoma & 482 & 35.0 \\
\hline No abnormal histopathological findings & 71 & 5.2 \\
\hline *The total number of histopathological diagnoses exceeds that of the patients studied, because sever- \\
al patients had more than one pathology concomitantly. Overall, 1179 patients had a histologically- \\
based diagnosis other than endometriosis.
\end{tabular}

tions; yet, certainly, we could rule out the diagnosis of genital tuberculosis because of the absence of characteristic lesions (i.e. caseating granuloma; reviewed in ref. 22) in the tissues obtained from suspected organ (tube, ovary, and peritoneum) sites during laparoscopy (data not shown). Beside to pointing out the cultural negativity of all our samples, these findings led us to focus the bulk of our discussion onto CT infection, given also the not too scarce number of peritoneal fluid samples found positive for a CT-specific NAAT (see below).

It is notorious that CT infection is linked to serious reproductive pathologies, including PID, ectopic pregnancy, and infertility, in women (19). To prevent the ascension of the chlamydial organism into the upper genital tract, women with a CT diagnosis, usually made by using NAAT on the endocervical swab (4), should be promptly and appropriately treated. In agreement, triage of women screened by the gynecologist for infertility/subfertility and laparoscopy is advised to include preliminarily the CT antibody testing (2). Nonetheless, the performance of current serological tests may limit the assessment of the burden of chlamydial infertility (19); yet, regardless of test performance, a recent analysis of estimates, based on the serological (antibody) evidence from previously published data, showed that the proportion of tubal factor infertility episodes due to CT infection is $45 \%$ (credible interval, 28 to $62 \%$ ) (24). Accordingly, CT antibody testing allowed to predict at least one normal tube in $100 \%$ of infertile women without history of abdominal or pelvic surgery, PID, and endometriosis (25). While CT ascension may not be the primary pathological determinant, it is certainly involved in the development of tubal pathology; yet, the presence of CT organism in the fallopian tubes is often unnoticed due to the difficulties of specimen collection from the upper genital tract (19).

Some decades ago, studies conducted in Italy reported the CT positivity (determined by McCoy cell culture method) in samples from the fallopian tubes of infertile women, suggesting that tubal sampling should have been included in the routine workup for infertility $(16,17)$.

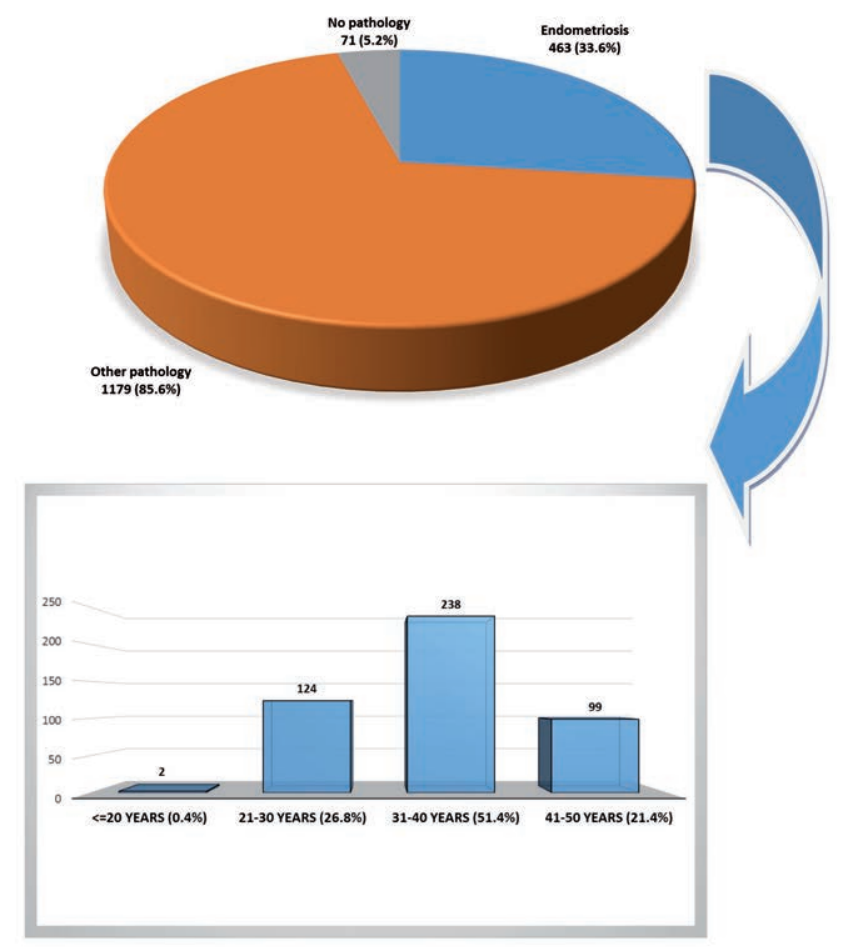

Figure 2. Endometriosis cases among the patient population studied and their distribution according to patients' age groups. 
Since that time, no evidences were further available except for one study by Villagrana Zesati et al. (26), published in Spanish language in 2013. The authors, indeed, documented the persistence of CT-specific DNA (i.e. OmpA gene) in endometrium and peritoneal-fluid, but not cervical-swab, samples of infertile patients. Surprisingly, clinical sampling of peritoneal fluid is a currently adopted practice at the time of diagnostic and/or surgical laparoscopy, particularly in Italian gynecological settings, of which the present study provides a valuable example. In this context, the peritoneum or the Douglas's pouch could represent an additional intracellular niche (17) for a highly evolved or ancient pathogen such as CT (19), supporting the notion that CT organisms are able to persist (and grow slowly) in a range of human cell types including macrophages and mucosal epithelial cells (10). Noteworthy, in one study, the rate of CT infection in infertile women has not increased following the sampling from multiple sites (cervix, urethra, high vagina, fimbriae, and the Douglas cavity), which suggested that routine PCR testing for CT should be confined to cervical sampling (7).

The overall prevalence of CT in our study was $2.2 \%$. Although the McCoy cell culture-based method has been traditionally considered as the gold standard for CT detection, NAATs offer greatly expanded sensitivities of detection (usually well above $90 \%$ ), while maintaining very high specificity (usually $\geq 99 \%$ ) (15). Nonetheless, culture for CT is quite specific, but this contrasts with the fact that samples of tubal washings/exudates are typically culture negative (14). The APTIMA CT assay, used in the present study, is a second generation NAAT; it utilizes target capture, transcription-mediated amplification, and hybridization protection assay technologies to amplify chlamydial specific rRNA, which is then indicative of the presence of viable organisms. For this reason, the percentage of CT positive samples in our study was higher than that reported by other investigators $(6,7,23)$. In a prospective study by Dietrich et al. (7), CT was detected in the cervical, vaginal, and urethral specimens of $2(0.9 \%)$ of 202 women; one patient with tubal occlusion of both tubes had a history of PID, and the other patient with tubal occlusion of one tube had no history of PID. In the same study, 42 (20.8\%) of 202 patients had serum samples that tested positive for CT antibodies, whereas only 1 of the 2 above-mentioned patients had CT antibodies (7). It should be noted that APTIMA CT assay is US FDAcleared for clinical use on cervical, vaginal, and male urethral swab specimens, as well as female and male urine specimens. However, testing of additional reproductive tract specimens using a commercially available NAAT is not unadvised (18), provided that laboratories are in compliance with CLIA for test modifications (4). We are aware that all APTIMA CT test results of the present study were interpreted by clinicians within the context of the patient-specific information to determine appropriate patient management (data not shown).

To our knowledge, this is the first largest survey of peritoneal fluid

Table 2. Determination of strength of association between Chlamydia trachomatis-positive peritoneal fluid and gynecological pathology in women.

\begin{tabular}{|c|c|c|c|}
\hline Histological findings & No. positive for CT & No. negative for CT & Odds ratio $(95 \% \mathrm{CI})$ \\
\hline No pathology & 3 & 86 & 1.00 (reference) \\
\hline $\begin{array}{l}\text { Any pathology, of which only...* } \\
\text {...endometriosis } \\
\text {...non-endometriosis }\end{array}$ & $\begin{array}{l}27 \\
10 \\
15\end{array}$ & $\begin{array}{l}1261 \\
254 \\
810\end{array}$ & $\begin{array}{l}0.61(0.18-2.06) \\
1.13(0.30-4.20) \\
0.53(0.15-1.87)\end{array}$ \\
\hline
\end{tabular}

*Two of 27 women with a Chlamydia trachomatis (CT) positive result and 197 of 1261 women with a CT negative result were excluded from the analysis for pathology-based categories, because of the concomitant presence of endometriosis and non-endometriosis pathologies in these women.

Table 3. Studies evaluating the association between Chlamydia trachomatis infection and endometriosis using different sample diagnostics.

\begin{tabular}{|c|c|c|c|c|c|c|}
\hline Author (year) & $\begin{array}{l}\text { No. of women } \\
\text { studied } \\
\text { in total }\end{array}$ & $\begin{array}{l}\text { No. of women } \\
\text { with pelvic } \\
\text { pathology }^{\mathrm{a}}\end{array}$ & $\begin{array}{l}\text { Type(s) of sample } \\
\text { (no. tested } \\
\text { positive/total) }\end{array}$ & $\begin{array}{l}\text { Microbiological } \\
\text { test/parameter } \\
\text { evaluated }^{\mathrm{c}}\end{array}$ & $\begin{array}{l}\text { Finding of } \\
\text { association: }\end{array}$ & Ref. \\
\hline Kligman (1996) & $\begin{array}{l}68 \text { (26 pelvic adhesions, } \\
16 \text { normal pelvis, } \\
4 \text { ovarian cyst, } 3 \text { myoma) }\end{array}$ & 19 & Peritoneal fluid (2/68) & $\begin{array}{l}\text { ELISA/IgG antibodies; } \\
\text { Hsp60 host response }\end{array}$ & No; yes & 12 \\
\hline Debattista (2004) & $\begin{array}{c}44 \text { (4 with severe tubal } \\
\text { obstructions } \\
\text { on falloposcopy) }\end{array}$ & 40 & $\begin{array}{l}\text { Cervical swab (0/39); } \\
\text { fallopian tube fluid }(7 / 44) \text {; } \\
\text { serum }(7 / 44)\end{array}$ & $\begin{array}{l}\text { PCR/DNA; ELISA/IgG, } \\
\text { IgA antibodies; } \\
\text { ELISA/IgG, } \\
\text { IgA antibodies }\end{array}$ & $\begin{array}{c}\text { Not evaluable; no } \\
\text { (combined results by tests); } \\
\text { no (combined results } \\
\text { by tests) }\end{array}$ & ); \\
\hline Oppelt (2010) & $\begin{array}{l}69 \text { (13 non-endometriosis } \\
\text { controls) }\end{array}$ & 56 & $\begin{array}{l}\text { Peritoneal, ovarian, or } \\
\text { endometrium lesion } \\
\text { tissue }(0 / 69)\end{array}$ & PCR/MOMP DNA & Not evaluable & 23 \\
\hline Gazvani (2011) & 51 & 51 & $\begin{array}{c}\text { Serum (-); } \\
\text { peritoneal fluid (-) }\end{array}$ & $\begin{array}{l}\text { ELISA/IgG, IgA antibodies; } \\
\text { ELISA/IgG, IgA antibodies }\end{array}$ & No; no & $\begin{array}{l}8 \text { [Article in } \\
\text { Cambodian] }\end{array}$ \\
\hline Dragic (2016) & $\begin{array}{l}1377 \text { (corresponding to } \\
1179 \text { ovarian (other), tubal, } \\
\text { or uterine pathology cases, } \\
\text { and } 71 \text { normal pelvis cases) }\end{array}$ & 463 & Peritoneal fluid (30/1377) & $\begin{array}{c}\text { Target nucleic acid } \\
\text { amplification probe/rRNA }\end{array}$ & No & This study \\
\hline
\end{tabular}


samples of women laparoscopically and/or histologically diagnosed with various reproductive pathologies, encompassing $\sim 35 \%$ of endometriosis and another $\sim 61 \%$ of various pathologies that affect the ovary and other upper genital tract parts. According to the Haas et al.'s study (9), $78.6 \%$ of our women with endometriosis fall into the premenopausal group (age, $\leq 40$ years) and $21.4 \%$ into perimenopausal group (age, 41 to 50 years). The relationship between endometriosis and bacterial infection, that has been prompted by the high incidence of disease together with the observation of pathological lesions resembling punctate blister-like lesions (23), was not clarified until recently. We reviewed, and compared our results with those of four studies aimed at elucidating the role of CT infection in women with endometriosis. Despite the paucity of studies which were the object of our qualitative synthesis, the 20-year temporal interval between the first study (published in 1996) and our study (published presently) denotes either a renewed or always alive interest to this topic. It is relevant that, in almost all of these studies $(6,8,12,23)$, the clinical samples used were peritoneal or tubal fluids/tissues, which were tested alone (12; this study) and in combination with cervical (6) and serum $(6,8)$ samples or with tissue samples from ovarian and endometrium lesions (23). Consistent with these studies, we found that endometriosis was not associated with peritoneal CT infection in women undergoing either a fertility or non-fertility diagnostic workup.

Therefore, endometriosis could be linked with fallopian tube damage (and infertility) significantly, but independently on the chlamydial presence in the peritoneal cavity (3). It is possible that CT triggers a chronic pelvic inflammation, which is essential to the development (and progression) of endometriosis, perhaps through an increased number of activated macrophages and specific cytokine/chemokine profiles (11). In the meantime, the $\mathrm{CT}$ infection-induced immune response (i.e. production of interferon-gamma and pro-inflammatory cytokines) would result in the interruption of chlamydial intracellular replication, the entering of Chlamydia cells into a persistent state, and the consequent inactivation of most chlamydial genes (14). Otherwise, the long-term release of chlamydial heat shock protein 60 , which is associated with the nonreplicative, intracellular persistent CT state, may induce a local proinflammatory immune response in the fallopian tube epithelium, which leads to scar formation and tubal occlusion (10).

In conclusion, our data confirm that the likelihood of finding CT RNA (or DNA) in clinical samples remains low and sporadic, thereby undermining our capability to assess the clinical significance of CT positivity, particularly when a cross-sectional study is performed. As laparoscopy and biopsy with histological confirmation is to date the primary investigation for endometriosis and other pelvic diseases/conditions (5), the sampling of peritoneal fluid during laparoscopy is not overcharged by surgeon's operational difficulty and patient's risk excess. However, performing microbiological tests on peritoneal fluid samples can be frustrating, and not cost-effective, in view of positivity rates of even zero for NG and MT organisms. If abolition of a well-consolidated clinical practice is more frustrating and then not realizable, it is advised that physicians limit peritoneal fluid sampling only to young women with endometriosis, for whom a positive CT result could be useful to guide clinical and/or therapeutic decisions. In the future, prospective clinical studies using molecular diagnosis of CT infection will serve to definitely clarify the pathway of infection through endometriosis and the development of sequelae leading to infertility.

\section{References}

1. Apari P, de Sousa JD, Müller V. Why sexually transmitted infections tend to cause infertility: an evolutionary hypothesis. PLoS Pathog 2014;10:e1004111.
2. Asner SA, Morré SA, Bochud PY, Greub G. Host factors and genetic susceptibility to infections due to intracellular bacteria and fastidious organisms. Clin Microbiol Infect 2014;20:1246-53.

3. Briceag I, Costache A, Purcarea VL, et al. Fallopian tubes--literature review of anatomy and etiology in female infertility. J Med Life 2015;8:129-31.

4. Centers for Disease Control and Prevention. Recommendations for the laboratory-based detection of Chlamydia trachomatis and Neisseria gonorrhoeae: 2014. MMWR Recomm Rep 2014;63:1-19.

5. Coleman L, Overton C. GPs have key role in early diagnosis of endometriosis. Practitioner 2015;259:13-7.

6. Debattista J, Gazzard CM, Wood RN, et al. Interaction of microbiology and pathology in women undergoing investigations for infertility. Infect Dis Obstet Gynecol 2004;12:135-45.

7. Dietrich W, Rath M, Stanek G, et al. Multiple site sampling does not increase the sensitivity of Chlamydia trachomatis detection in infertility patients. Fertil Steril 2010;93:68-71.

8. Gazvani R, Coyne L, Anttila T, et al. Antibodies to Chlamydia trachomatis in serum and peritoneal fluid of women with endometriosis. Hum Fertil (Camb) 2011;14:64-7.

9. Haas D, Chvatal R, Reichert B, et al. Endometriosis: a premenopausal disease? Age pattern in 42,079 patients with endometriosis. Arch Gynecol Obstet 2012;286:667-70.

10. Hafner LM. Pathogenesis of fallopian tube damage caused by Chlamydia trachomatis infections. Contraception 2015;92:108-15.

11. Jin $\mathrm{CH}$, Yi KW, Ha YR, et al. Chemerin expression in the peritoneal fluid, serum, and ovarian endometrioma of women with endometriosis. Am J Reprod Immunol 2015;74:379-86.

12. Kligman I, Grifo JA, Witkin SS. Expression of the $60 \mathrm{kDa}$ heat shock protein in peritoneal fluids from women with endometriosis: implications for endometriosis-associated infertility. Hum Reprod 1996;11:2736-8.

13. Lal JA, Malogajski J, Verweij SP, et al. Chlamydia trachomatis infections and subfertility: opportunities to translate host pathogen genomic data into public health. Public Health Genomics 2013;16:50-61.

14. Linhares IM, Witkin SS. Immunopathogenic consequences of Chlamydia trachomatis $60 \mathrm{kDa}$ heat shock protein expression in the female reproductive tract. Cell Stress Chaperones 2010;15:467-73.

15. Ljubin-Sternak S, Meštrović T. Chlamydia trachomatis and genital mycoplasmas: pathogens with an impact on human reproductive health. J Pathog 2014;2014:183167.

16. Lucisano A, Morandotti G, Marana R, et al. Chlamydia genital infections and laparoscopic findings in infertile women. Eur J Epidemiol 1992;8:645-9.

17. Marana R, Lucisano A, Leone F, et al. High prevalence of silent Chlamydia colonization of the tubal mucosa in infertile women. Fertil Steril 1990;53:354-6.

18. Marangoni A, Foschi C, Nardini P, et al. Evaluation of the Versant CT/GC DNA 1.0 assay (kPCR) for the detection of extra-genital Chlamydia trachomatis and Neisseria gonorrhoeae infections. PLoS One 2015;10:e0120979.

19. Menon S, Timms P, Allan JA, et al. Human and pathogen factors associated with Chlamydia trachomatis-related infertility in women. Clin Microbiol Rev 2015;28:969-85.

20. National Collaborating Centre for Women's and Children's Health (UK). Fertility: assessment and treatment for people with fertility problems. London: Royal College of Obstetricians \& Gynaecologists; 2013.

21. Newman L, Rowley J, Vander Hoorn S, et al. Global estimates of the prevalence and incidence of four curable sexually transmitted infections in 2012 based on systematic review and global reporting. PLoS One 2015;10:e0143304.

22. Nezar M, Goda H, El-Negery M, et al. Genital tract tuberculosis 
among infertile women: an old problem revisited. Arch Gynecol Obstet 2009;280:787-91.

23. Oppelt P, Renner SP, Strick R, et al. Correlation of high-risk human papilloma viruses but not of herpes viruses or Chlamydia trachomatis with endometriosis lesions. Fertil Steril 2010;93:1778-86.

24. Price MJ, Ades AE, Welton NJ, et al. How much tubal factor infertility is caused by Chlamydia? Estimates based on serological evidence corrected for sensitivity and specificity. Sex Transm Dis 2012;39:608-13.
25. Raoofi Z, Barchinegad M, Haghighi L. The value of negative Chlamydia trachomatis antibody in prediction of normal tubes in infertile women. Clin Exp Obstet Gynecol 2013;40:95-7.

26. Villagrana Zesati JR, López Hurtado M, Flores Salazar VR, et al. [Persistence of Chlamydia trachomatis in endometrium and peritoneal fluid of infertile patients with negative cervical culture]. Ginecol Obstet Mex 2013;81: 23-8. [Article in Spanish]

27. Wiesenfeld HC, Hillier SL, Meyn LA, et al. Subclinical pelvic inflammatory disease and infertility. Obstet Gynecol 2012;120:37-43. 